\title{
Fits in hydrocephalic children
}

\author{
GWILYM P. HOSKING \\ From the Department of Neurology, Alder Hey Children's Hospital, Liverpool
}

\begin{abstract}
Hosking, G. P. (1974). Archives of Disease in Childhood, 49, 633. Fits in hydrocephalic children. A retrospective study of 200 hydrocephalic children suggests that the incidence of fits in these children is approximately $30 \%$. The need for frequent valve revision appeared to increase the tendency towards fits occurring, as did an aetiology of meningitis.
\end{abstract}

Uncertainty appears to exist as to the frequency of fits in hydrocephalic children. While some standard textbooks of paediatrics and neurology describe fits as being common in these children (Brain and Walton, 1969; Ford, 1966), reports have appeared which suggest that, though abnormal EEGs may be common, fits in untreated hydrocephalics at least are not common (Fois, Gibbs, and Gibbs, 1958; Pampiglione and Lawrence, 1962). Recently, a comparison of a small number of children and adults with treated and untreated hydrocephalus suggested that fits were common, and were more common after the insertion of a ventriculo-atrial shunt (Graebner and Celesia, 1973). It was therefore decided to attempt to ascertain the frequency of fits in hydrocephalic children by means of a retrospective study.

\section{Methods}

A study was made of the case records of 200 randomly selected children with hydrocephalus who were referred in infancy to the Liverpool Regional Neonatal Surgical Unit and the Department of Neurology at Alder Hey Children's Hospital between 1960 and 1970. 100 of these patients had spina bifida with meningocele or myelomeningocele. The remaining 100 children developed hydrocephalus secondary to either meningitis in infancy or cerebral haemorrhage in the neonatal period, or else they fitted into the 'primary' or 'congenital' group with no apparent aetiology.

Children who did not survive for more than 6 months were not included in the study as it was felt that the information would have been unhelpful.

The majority, 197, were treated in early infancy with a ventriculo-atrial or a ventriculo-pleural shunt incorporating a Spitz-Holter valve. At the time of the study most of the children had been followed up for a period of well over 5 years.

Received 21 January 1974.

\section{Results}

The children in the study were split into two main groups. Group A consisted of patients who had hydrocephalus in association with spina bifida (100 patients), while group B consisted of those who developed hydrocephalus secondary to either meningitis or haemorrhage in the neonatal period, or who fitted into the 'primary' group (100 patients). Table I shows the overall frequency of fits in the 200

TABLE I

Incidence of fits (200 patients)

\begin{tabular}{l|c|c}
\hline & Group A* & Group B十 \\
\hline M : F & $48: 52$ & $65: 35$ \\
Fits & 26 & 35 \\
No fits & 74 & 65 \\
Total & 100 & 100 \\
\hline
\end{tabular}

*Hydrocephalus with spina bifida. tHydrocephalus secondary to meningitis or haemorrhage, or no apparent aetiology.

Note: Overall incidence $61 / 200(30 \cdot 5 \%)$.

children studied. The frequency of fits in groups A and $B$ of $26 \%$ and $35 \%$, respectively, did not differ significantly.

In Table II are the ages of inception of the fit or

TABLE II

Inception ages for fits

\begin{tabular}{c|c|c}
\hline Age (yr) & Group A (no. = 26) & Group B (no. = 35) \\
\hline$<1$ & 4 & 8 \\
$1-5$ & 18 & 21 \\
$>5$ & 4 & 6 \\
& & $(2$ over 10 yr) \\
\hline
\end{tabular}

fits in the two groups, and in the majority this was below 5 years. However, the average length of 
follow-up at the time of the study was variable due to the differing ages of the children and the relatively high mortality (Table III).

TABLE III

Length of follow-up for patients at time of study

\begin{tabular}{c|c|c}
\hline Age (yr) & Group A (no. = 100) & Group B (no. = 100) \\
\cline { 2 - 3 }$<1$ & 4 & 4 \\
$1-5$ & 15 & 21 \\
$5-10$ & 50 & 27 \\
$10-13$ & 31 & 48 \\
\hline
\end{tabular}

A small number of patients in both groups were noted to have had fits in relation to valve blockage ( 5 in each group). 2 patients in group A were diagnosed as having had 'infantile spasms', while the remaining patients had either single fits with or without fever or recurrent fits. Consideration was given to factors that possibly influenced the tendency for fits to occur.

Table IV shows the average number of valve revisions in the two major groups, divided into those

TABLE IV

Average number of valve revisions per patient

\begin{tabular}{l|c|c}
\hline & Group A & Group B \\
\hline Overall & $1.29(118 / 91)$ & $0.95(90 / 94)$ \\
Had fits & $2.00(50 / 25)$ & $1.67(52 / 31)$ \\
No fits & $1.03(68 / 66)$ & $0.60(38 / 63)$ \\
\hline
\end{tabular}

Note: Children who did not have valves inserted ( 3 out of 200) or who had them inserted but subsequently removed ( 8 out of 200 ) have not been included.

who had fits and those who did not. The average number of revisions in both subgroups of children with fits was significantly greater than in those who did not have fits $(P<0.001$ for each group).

Since the aetiology of the hydrocephalus might have been expected to influence the tendency towards fits, group B was subdivided into three aetiological groups: primary (62), secondary to haemorrhage (14), and secondary to meningitis (24). The incidence of fits in the three aetiological groups is shown in Table V.

TABLE V

Group $B$, incidence of fits in aetiological groups

\begin{tabular}{l|c|c|c}
\hline & Primary & $\begin{array}{c}\text { Secondary to } \\
\text { haemorrhage }\end{array}$ & $\begin{array}{c}\text { Secondary to } \\
\text { meningitis }\end{array}$ \\
\hline $\begin{array}{l}\text { No. of patients } \\
\text { Had fits }\end{array}$ & $\begin{array}{c}62 \\
17 / 62(27 \%)\end{array}$ & $5 / 14(35 \%)$ & $13 / 24(54 \%)$ \\
\hline
\end{tabular}

In the primary group the incidence of fits was $27 \%$, while in the postmeningitis group the incidence was $54 \%$, significantly higher than in the primary group $\left(\chi^{2}=16 \cdot 7, \mathrm{P}<0.001\right)$. In the posthaemorrhage group $35 \%$ had fits, and this incidence was not significantly greater than in the primary group. There was a high mortality in both major groups studied (Table VI).

TABLE VI

Mortality in both major groups

\begin{tabular}{c|c|c}
\hline Age (yr) & Group A (no. = 100) & Group B (no. = 100) \\
\hline$<1$ & 4 & 4 \\
$1-5$ & 14 & 20 \\
\hline
\end{tabular}

\section{Causes of death.}

The causes of death in the two groups were as follows.

Group A. 4 raised intracranial pressure, 6 septicaemia, 3 cause unknown, 2 pneumonia, 1 ventriculitis, 1 cerebral haemorrhage, 1 postoperative (valve revision).

Group B. 6 raised intracranial pressure, 4 septicaemia, 6 cause unknown, 4 pneumonia, 6 ventriculitis.

\section{Discussion}

The incidence of fits in the child population has been estimated in a number of large population studies (Miller et al., 1960; Cooper, 1965; Van den Berg and Yerushalmy, 1969; Ross, 1973). In the under 5 year olds a figure of about $3 \%$ appears to be an approximation of the proportion of the children that have a fit or fits, either febrile or nonfebrile, though the Newcastle ' 1000 family survey' in 1960 suggested a figure of $7 \cdot 2 \%$ (Miller et al., 1960). Fois et al. (1958), in an EEG study, noted only 2 children out of 32 with hydrocephalus that had fits. Pampiglione and Lawrence (1962), in a similar study, noted only 3 out of 50 children with fits. Hunt et al. (1973) mentioned in a footnote in their paper on the predictive value of sensory levels in open myelomeningoceles that 15 of $73(20.5 \%)$ children treated with ventriculo-atrial shunts had 'epilepsy'.

Some authors have suspected that the ventricular catheters in the surgically treated patients with hydrocephalus form an epileptic focus (Laws and Neidermeyer, 1970; Graebner and Celesia, 1973). Graebner and Celesia's study was of 39 patients of very variable ages ( 3 days to 66 years, mean $13 \cdot 3$ years) whose hydrocephalus was of mixed aetiology. Approximately half were studied without shunts and 
half with shunts. $62 \%$ of patients without shunts had abnormal EEGs, while $85 \%$ of the shunted patients had abnormal EEGs, with $38 \%$ of the shunted patients having focal abnormalities in the area of their ventricular catheter. $20 \%$ of the patients without shunts had fits, while $48 \%$ of the shunted patients had fits. No mention was made of the severity of the hydrocephalus in the untreated group.

This survey of hydrocephalic children suggests that the overall frequency of fits is about $30 \%$. This figure is an approximation only, as those dying before the age of 6 months were not included in the study. The true figure is therefore probably higher. Identifying specific factors in hydrocephalic children that affect the tendency to fits can be difficult because so many factors operate in any one case ( $R$. Harris, personal communication, 1973).

- In this study the need for more frequent valve revisions appeared to increase the tendency towards fits and an aetiology of meningitis also appeared to increase that tendency.

I particularly thank Dr. J. Rees Roberts for support throughout the study, Dr. T. M. Mawdsley for access to records from the Spina Bifida Clinic, and others who work with hydrocephalic children, both at the Alder Hey Hospital and elsewhere, who took an interest in this study and provided valuable comments. Mrs. Barbara Moore and Miss Barbara Addicott gave invaluable assistance.

\section{REFERENCES}

Brain, W. R., and Walton, J. N. (Editors) (1969). Brain's Diseases of the Nervous System, 7th ed., p. 208. Oxford Medical Publications, Oxford.

Cooper, J. E. (1965). Epilepsy in a longitudinal survey of 5,000 children. British Medical fournal, 1, 1020.

Fois, A., Gibbs, E. L., and Gibbs, F. A. (1958). Bilaterally independent sleep patterns in hydrocephalus. Archives of Neurology and Psychiatry, 79, 264.

Ford, F. R. (Editor) (1966). Diseases of Nervous System in Infancy, Childhood and Adolescence, 5th ed., p. 77. Thomas, Springfield, Illinois.

Graebner, R. W., and Celesia, G. G. (1973). E.E.G. findings in hydrocephalus and their relation to shunting procedures. Electroencephalography and Clinical Neurophysiology, 35, 517.

Hunt, G., Lewin, W., Gleave, J., and Gairdner, D. (1973). Predictive factors in open myelomeningocoele with special reference to sensory level. British Medical fournal, 4, 197.

Laws, E. R., and Neidermeyer, E. (1970). E.E.G. findings in hydrocephalic patients with shunt procedures. (Abst.) Electroencephalography and Clinical Neurophysiology, 29, 325.

Miller, F. J. W., Court, S. D. M., Walton, W. S., and Knox, E. G. (1960). Growing up in Newcastle on Tyne, p. 164. Oxford University Press, London.

Pampiglione, G., and Lawrence, K. M. (1962). Electroencephalographic and clinicopathological observations in hydrocephalic children. Archives of Disease in Childhood, 37, 491.

Ross, E. M. (1973). Convulsive disorders in British children. Proceedings of the Royal Society of Medicine, 66, 703.

Van den Berg, B. J., and Yerushalmy, J. (1969). Studies on convulsive disorders in young children. Pediatric Research, 3, 298.

Correspondence to Dr. G. P. Hosking, The National Hospital for Nervous Diseases, Queen Square, London WC1N 3BG. 